\title{
Case finding for chronic obstructive pulmonary disease: a model for optimising a targeted approach
}

\author{
Rachel E Jordan, ${ }^{1}$ Kin-bong Hubert Lam, ${ }^{1}$ Kar Keung Cheng, ${ }^{1}$ Martin R Miller, ${ }^{2}$ \\ Jennifer L Marsh, ${ }^{1}$ Jon G Ayres, ${ }^{3}$ David Fitzmaurice, ${ }^{4}$ Peymané Adab ${ }^{1}$
}

- Supplementary tables are published online only. To view these files please visit the journal online (http://thorax.bmj. com).

${ }^{1}$ Unit of Public Health, Epidemiology \& Biostatistics, University of Birmingham, UK ${ }^{2}$ Department of Medicine, University Hospital Birmingham NHS Trust, Birmingham, UK ${ }^{3}$ Institute of Occupational and Environmental Medicine, University of Birmingham, UK ${ }^{4}$ Primary Care Clinical Sciences, University of Birmingham, UK

\section{Correspondence to}

Dr Rachel Jordan, Unit of Public Health, Epidemiology \& Biostatistics, Public Health Building, University of Birmingham, Edgbaston, Birmingham B15 2TT, UK; r.e.jordan@bham.ac.uk

Received 15 October 2009 Accepted 23 March 2010

\section{ABSTRACT}

Objectives Case finding is proposed as an important component of the forthcoming English National Clinical Strategy for chronic obstructive pulmonary disease (COPD) because of accepted widespread underdiagnosis worldwide. However the best method of identification is not known. The extent of undiagnosed clinically significant COPD in England is described and the effectiveness of an active compared with an opportunistic approach to case finding is evaluated. Methods A cross-sectional analysis was carried out using using Health Survey for England (HSE) 1995-1996 data supplemented with published literature. A model comparing an active approach (mailed questionnaires plus opportunistic identification) with an opportunisticonly approach of case finding among ever smokers aged 40-79 years was evaluated. There were 20496 participants aged $\geq 30$ years with valid lung function measurements. The main outcome measure was undiagnosed clinically significant COPD lany respiratory symptom with both forced expiratory volume in $1 \mathrm{~s}$ $\left(\mathrm{FEV}_{1}\right) /$ forced vital capacity $(\mathrm{FVC})<0.7$ and $\mathrm{FEV}_{1}<80 \%$ predicted).

Results 971 (4.7\%) had clinically significant COPD, of whom 840 (86.5\%) did not report a previous diagnosis. Undiagnosed cases were more likely to be female, and smoked less. $25.3 \%$ had severe disease $\left(\mathrm{FEV}_{1}<50 \%\right.$ predicted), 38.5\% Medical Research Council (MRC) grade 3 dyspnoea and $44.1 \%$ were current smokers. The active case-finding strategy can potentially identify $70 \%$ more new cases than opportunistic identification alone (3.8 vs 2.2 per 100 targeted). Treating these new cases could reduce hospitalisations by at least 3300 per year in England and deaths by 2885 over 3 years.

Conclusions There is important undiagnosed clinically significant COPD in the population, and the addition of a systematic case-finding approach may be more effective in identifying these cases. The costeffectiveness of this approach needs to be tested empirically in a prospective study.

\section{INTRODUCTION}

Chronic obstructive pulmonary disease (COPD) affects $5-10 \%$ of the population worldwide, ${ }^{1}$ with a rising prevalence, and is a leading cause of mortality. In the UK, COPD accounts for 1.4 million general practitioner (GP) consultations and 1 million inpatient bed days annually, costing the National Health Service (NHS) $>£ 800$ million. $^{2}$ Recently COPD has received increasing attention as an important condition in England, culminating in a National Clinical Strategy due to be published later this year. ${ }^{3}$ Global underdiagnosis, ranging between
$45 \%$ and $85 \%,{ }^{4-6}$ is widely reported, and recently the British Lung Foundation has led a drive to identify these 'missing millions'. However, population screening using spirometry is not recommended ${ }^{7}$ because it would identify many people without clinically significant symptoms for whom there is little evidence of effective interventions. ${ }^{8}$ Evidence for progression of asymptomatic cases to clinically significant disease is also conflicting.

Nevertheless it is likely that there are people with unmet healthcare needs, who have clinically significant COPD, but are unknown to the health services These patients may potentially benefit from known effective interventions (including inhaled treatment pulmonary rehabilitation and smoking cessation), ${ }^{89}$ which could offer symptomatic relief, modify disease progression and improve quality of life. UK National Institute for Health and Clinical Excellence (NICE) guidelines recommend that a diagnosis of COPD should be considered in patients with chronic respiratory symptoms and risk factors. ${ }^{9}$ Such opportunistic case finding is likely to be sporadically implemented, but will miss patients not consulting their GP. There might be a case for more systematic targeted case finding such as indicated in the preliminary report for the forthcoming National Clinical Strategy. ${ }^{3}$ A few studies have explored potential approaches in a range of different target groups, but the best approach for identifying undiagnosed cases is not known as these reports have not included comparison groups. ${ }^{10-13}$

The Health Survey for England (HSE) offers the potential for assessing the degree of underdiagnosis of COPD and for modelling various case-finding strategies. Although not designed for this purpose, it is a large data set, representative of the English population and in 1995 and 1996 included both spirometry and questions about respiratory symptoms.

The aim of this study is first, to use the HSE to quantify the extent of undiagnosed clinically significant COPD in England, and describe the characteristics of this population; and secondly to model and compare two COPD case-finding approaches in primary care, and to identify critical points in the model using sensitivity analyses. By informing the choice of case-finding approaches, the model generated could be applied to similar countries in Europe and North America.

\section{METHODS \\ Study design and participants}

This was a cross-sectional analysis of data collected by the HSE (1995 and 1996). 
The HSE is an annual survey which monitors the health of the nation. A general population sample is obtained by multistage stratified random sampling of private households in England $^{14} 15$ with standardised home interviews and health assessments administered by trained interviewers/nurses. In 1995-1996, >32 000 adults participated. Data were obtained from the UK Data archive combining both years. Participants aged $\geq 30$ years with valid lung function and height data were included.

\section{Procedures}

Information was obtained on demographic factors, lifestyle and health, including if they had diagnosed asthma, any (and which) longstanding illnesses and a range of respiratory symptoms. Smoking was defined as current, ex- and never regular smokers (regular defined as $\geq 1$ cigarette per day). Pack-years were calculated for all participants.

Pulmonary function tests, without reversibility, were performed according to a standard protocol ${ }^{14}{ }^{15}$ with a Vitalograph Escort spirometer (Fleisch pneumotachograph flow head) calibrated daily at normal room temperature.

\section{Definition of COPD}

In conformity with NICE guidelines, ${ }^{9}$ clinically significant COPD was defined as reporting of any respiratory symptom (exertional breathlessness, chronic cough, regular sputum, frequent winter bronchitis or wheeze) and evidence of airways obstruction on spirometry (forced expiratory volume in $1 \mathrm{~s}$ $\left(\mathrm{FEV}_{1}\right) /$ forced vital capacity (FVC) $<0.7$ and $\mathrm{FEV}_{1}<80 \%$ predicted (equivalent to Global Initiative for Chronic Obstructive Lung Disease (GOLD) stage $\mathrm{II}^{16}$ ). There is controversy over the criteria which should be used to define COPD, therefore analyses were repeated with different spirometric criteria, including GOLD $\left(\mathrm{FEV}_{1} / \mathrm{FVC}<0.7\right)$, single $\mathrm{LLN}\left(\mathrm{FEV}_{1} / \mathrm{FVC}\right.$ below the lower limit of normal $=5$ th percentile of the healthy never-smoking population, using the ECCS (European Community for Steel and Coal) reference equations) ${ }^{17}$ and double LLN ( $\mathrm{FEV}_{1} / \mathrm{FVC}$ and $\mathrm{FEV}_{1}$ values both below the lower limit of normal). ${ }^{18}$

Participants with airways obstruction and reporting a diagnosis of asthma, with first episode of wheeze before the age of 30 , were reclassified as 'not having COPD' to reduce misclassification of those with asthma. Those with clinically significant COPD who did not report having chronic bronchitis/emphysema were classified as being 'undiagnosed'.

\section{Development of a case-finding model \\ Target group}

Initial analyses showed that the prevalence of clinically significant COPD among never smokers and in those aged $<40$ years was low. As there are also practical difficulties in measuring lung function in elderly patients, the chosen target group for case finding in our model was current or ex-smokers aged 40-79 years without a prior self-report of chronic bronchitis/ emphysema. Although there are several screening tools published which include more complex methods for identifying undiagnosed COPD designed to increase specificity, ${ }^{19-21}$ none has been designed or validated with the clinical COPD definition used here. Consequently, this broad target group was chosen, allowing sensitivity analyses for more restrictive scenarios.

\section{Model details}

A simple model comparing an active case-finding approach with an opportunistic-only approach was developed using data from the HSE and published literature, and applied to a likely scenario in primary care with a hypothetical cohort of 10000 patients (figure 1). Patients in the target group would be identified from general practice records. With an opportunistic-only approach, each patient's notes would be flagged as a reminder for GPs/ practice nurses to ask simple questions during any consultation about relevant respiratory symptoms. This would be compared with the 'active' approach, consisting of both an opportunistic component (as above) and the addition of a postal questionnaire with the same respiratory questions.

Patients with positive respiratory symptoms (defined according to the NICE criteria as above) would be invited for spirometry and then classified as having COPD or not (definition as above). Assumptions for proportions entering each stage of the model were taken from the above HSE analyses or from the published literature (table 1). The model was based on a 1 year period, assuming the respiratory questions would be administered at one consultation.

\section{Model outcomes}

The main outcomes were: new cases detected as a percentage of patients targeted, difference in number of cases detected (per 100 targeted), proportion of total expected cases detected and

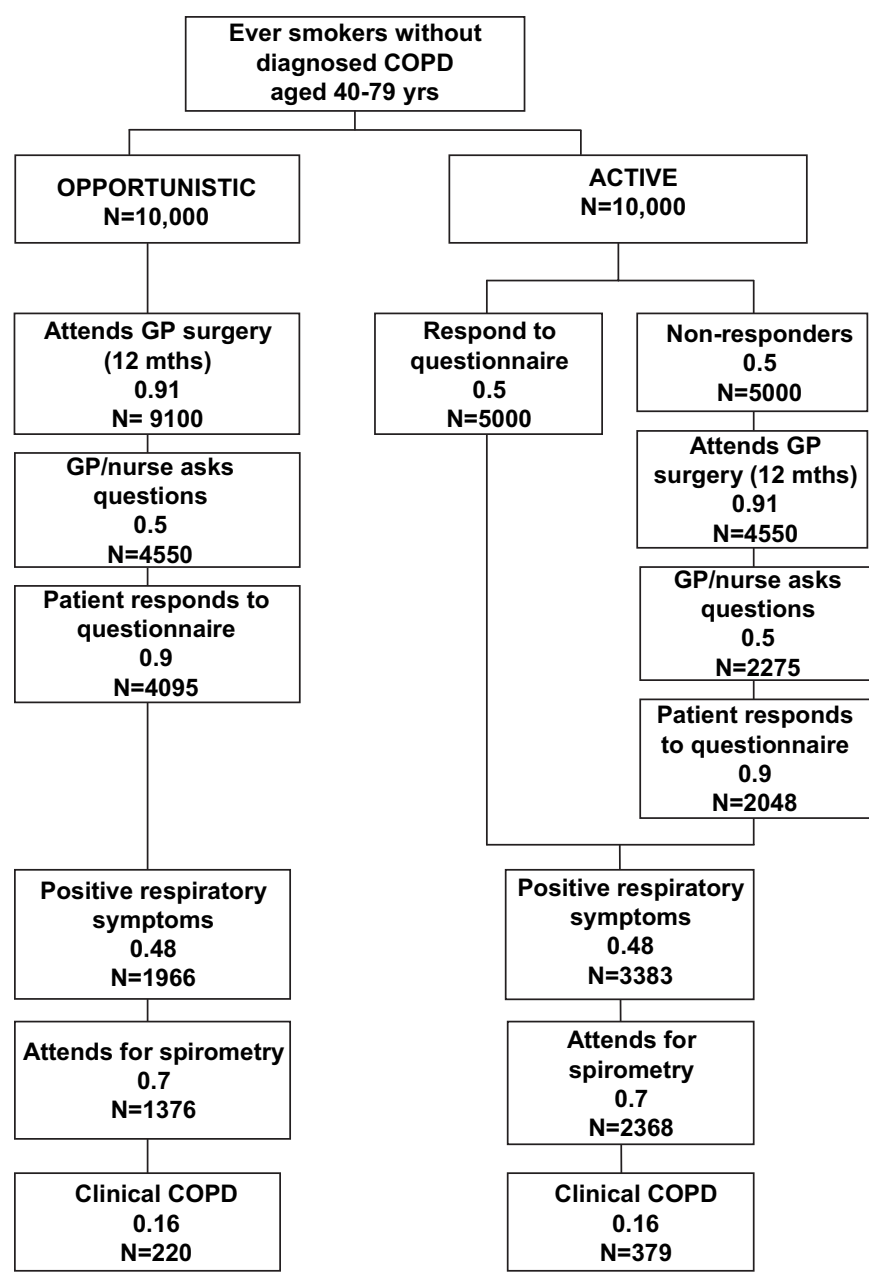

Figure 1 Model comparing an active approach with opportunistic-only approach with case finding in chromic obstructive pulmonary disease (COPD). Figures are proportions (based on estimates from sources detailed in table 1) and calculated numbers based on a hypothetical cohort of 10000 in each option. 
Table 1 Base case assumptions for model: among ever smokers aged 40-79 years without diagnosis of COPD

\begin{tabular}{|c|c|c|}
\hline & Base case & Source/explanation \\
\hline \multicolumn{3}{|l|}{ Proportion of cohort having respiratory symptoms } \\
\hline Dyspnoea & 0.32 & HSE analysis \\
\hline MRC grade 3 dyspnoea or worse & 0.13 & \\
\hline Chronic cough or phlegm & 0.21 & \\
\hline Any of the above & 0.48 & \\
\hline Proportion having childhood asthma & 0.04 & HSE analysis \\
\hline \multicolumn{3}{|l|}{ Proportion of COPD* with low $\mathrm{FEV}_{1}$ (\% predicted) } \\
\hline $50-79 \%$ & 0.73 & HSE analysis \\
\hline $30-49 \%$ & 0.23 & \\
\hline$<30 \%$ & 0.04 & \\
\hline Proportion of COPD* with MRC grade 3 dyspnoea or worse & 0.39 & HSE analysis \\
\hline Proportion of COPD* with either $\mathrm{FEV}_{1}<50 \%$ or MRC grade 3 dyspnoea & 0.51 & HSE analysis \\
\hline $\begin{array}{l}\text { Proportion of consultations where questionnaire is administered } \\
\text { opportunistically }\end{array}$ & 0.5 & Reported rates for atrial fibrillation screening with pulse $30-70 \%^{23} 26$ \\
\hline Response rate to questionnaire in surgery & 0.9 & Response rates $98-100 \%^{11} 1227$ \\
\hline Proportion attendance for spirometry & 0.7 & Uptake rates $33-97 \%^{512} 2327$ \\
\hline Sensitivity of spirometry test (quality compared with specialised technician) & 1.0 & $\begin{array}{l}\text { Possible } 3 \% \text { underdiagnosis }{ }^{28} \text { but literature suggests overdiagnosis most } \\
\text { common }\end{array}$ \\
\hline
\end{tabular}

${ }^{*}$ Clinically significant COPD is defined as respiratory symptoms and airways obstruction (National Institute for Health and Clinical Excellence criteria).

Estimates based on 1 year time period.

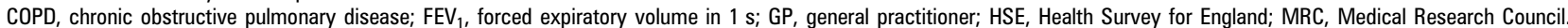

numbers needed to target (NNT; calculated as $1 /$ risk difference) for the active compared with the opportunistic approach. The proportion of new cases who would be expected to have stage III or IV disease ( $\mathrm{FEV}_{1}<50 \%$ predicted) or Medical Reseach Council (MRC) grade 3 or worse dyspnoea was also calculated in order to quantify the proportion most able to benefit from diseasemodifying treatment (treatment which can reduce exacerbations, hospitalisations or mortality). ${ }^{8}$

\section{Sensitivity analyses}

Sensitivity was assessed by considering the impact of varying each parameter individually within plausible ranges.

\section{Alternative targeting strategies}

The effects of alternative strategies were considered such as targeting different age groups, age-smoking combinations, symptom profiles and spirometric criteria. Estimates of input parameters were derived from the HSE.

\section{Statistical analyses}

Characteristics of undiagnosed and diagnosed patients with COPD were compared using $\chi^{2}$ tests.

\section{RESULTS}

\section{Characteristics and prevalence of undiagnosed COPD}

There were 20496 participants aged $\geq 30$ years with valid height and spirometry measurements, 9959 (48.6\%) from 1995 and 10537 (51.4\%) from 1996 (table 2). Mean age was 51.8 years (SD 14.8 ) and $53.0 \%$ were female. A quarter of participants were current smokers, and a further $6187(30.2 \%)$ were ex-smokers. A total of $2180(10.6 \%)$ reported ever having been diagnosed with asthma, and $6.3 \%$ that their first episode of wheeze was before the age of 30 . Although 8410 (41.0\%) reported at least one of the included respiratory symptoms, only $971(4.7 \%)$ also had airways obstruction, and were thus classified as having clinically significant COPD. Of these, only $131(13.5 \%)$ reported chronic bronchitis/emphysema, suggesting that $>85 \%$ were undiagnosed. Notably, although $291(1.4 \%)$ reported a diagnosis of chronic bronchitis/emphysema, less than half of these demonstrated airflow obstruction.

\section{Characteristics of participants with undiagnosed COPD}

Table 3 compares characteristics of participants with diagnosed and undiagnosed clinically significant COPD. Although there was a greater proportion of females among undiagnosed cases, this was not significant $(41.7 \%$ vs $35.9 \%, p=0.2)$; however, they were more likely to be never smokers $(16.8 \%$ vs $6.9 \%, p=0.002)$. They were less likely to report each of the specific respiratory symptoms and their dyspnoea was less severe $38.5 \%$ had MRC grade 3 dyspnoea vs $69.5 \%$ of those reporting a diagnosis). Although airways obstruction in undiagnosed cases was milder overall $(p<0.001)$, a quarter of these had severe airways obstruction $\left(\mathrm{FEV}_{1}<50 \%\right.$ predicted) and therefore under current guidance would be eligible for disease-modifying inhalers. ${ }^{13} 15$ Those with milder stage disease would be eligible for bronchodilators or mucolytics for symptomatic relief, ${ }^{15}$ while those with MRC grade 3 dyspnoea would be eligible for pulmonary rehabilitation..$^{15}$ In addition, $44.1 \%$ were current smokers, and would be eligible for smoking cessation therapy.

Prevalence of undiagnosed clinically significant COPD increased with age, from $0.2 \%$ (30-39 years group), to $12.9 \%$ ( $\geq 80$ years group). Prevalence was highest among smokers at all ages (figure 2), rising from age 40-45 years. Among ex-smokers, COPD prevalence remained at or below $1 \%$ until age 55 years, 
Table 2 Characteristics of participants

\begin{tabular}{|c|c|c|}
\hline Number of participants & 20496 & \\
\hline 1995 & $9959(48.6 \%)$ & \\
\hline 1996 & $10537(51.4 \%)$ & \\
\hline \multicolumn{3}{|l|}{ Age (years) } \\
\hline $30-39$ & $5340(26.1 \%)$ & \\
\hline $40-49$ & $4822(23.5 \%)$ & \\
\hline $50-59$ & $3821(18.6 \%)$ & \\
\hline $60-69$ & $3371(16.5 \%)$ & \\
\hline $70-79$ & $2365(11.5 \%)$ & \\
\hline$\geq 80$ & $777(3.8 \%)$ & \\
\hline \multicolumn{3}{|l|}{ Sex } \\
\hline Male & $9643(47.1 \%)$ & \\
\hline Female & $10853(53.0 \%)$ & \\
\hline \multicolumn{3}{|l|}{ Smoking status } \\
\hline Current & $5191(25.3 \%)$ & \\
\hline Ex-regular & $6187(30.2 \%)$ & \\
\hline Never regular & $9115(44.5 \%)$ & \\
\hline \multicolumn{3}{|l|}{ Reported respiratory conditions } \\
\hline Reported asthma diagnosis & $2180(10.6 \%)$ & \\
\hline $\begin{array}{l}\text { First wheezed before age } \\
30 \text { years }\end{array}$ & $1289(6.3 \%)$ & \\
\hline $\begin{array}{l}\text { Reported diagnosis of chronic } \\
\text { bronchitis or emphysema }\end{array}$ & $291(1.4 \%)$ & \\
\hline Other respiratory condition* & $489(2.4 \%)$ & \\
\hline \multicolumn{3}{|l|}{ Reported respiratory symptoms } \\
\hline Dyspnoea & $5425(26.5 \%)$ & \\
\hline MRC grade 3 or worse & $2223(10.9 \%)$ & \\
\hline Wheeze & $4422(21.6 \%)$ & \\
\hline Chronic cough & $2783(13.6 \%)$ & \\
\hline Chronic phlegm & $2181(10.6 \%)$ & \\
\hline Frequent winter bronchitis & $3447(16.8 \%)$ & \\
\hline $\begin{array}{l}\text { Any of the above respiratory } \\
\text { symptoms }\end{array}$ & $8410(41.0 \%)$ & \\
\hline \multicolumn{3}{|l|}{ Airways obstruction $\dagger$} \\
\hline GOLD & $2872(14.0 \%)$ & \\
\hline NICE & $1305(6.4 \%)$ & \\
\hline Single LLN & $1796(8.8 \%)$ & \\
\hline Double LLN & $733(3.6 \%)$ & \\
\hline Clinically significant COPD $†, \ddagger$ & & $\begin{array}{l}\text { Reporting diagnosis of chronic } \\
\text { bronchitis/emphysema }\end{array}$ \\
\hline GOLD+symptoms & $91628(7.9 \%)$ & $145(8.9 \%)$ \\
\hline NICE+symptoms & $971(4.7 \%)$ & $131(13.5 \%)$ \\
\hline Single LLN+symptoms & 1072 (5.2\%) & $113(10.5 \%)$ \\
\hline Double LLN+symptoms & $571(2.8 \%)$ & $99(17.3 \%)$ \\
\hline
\end{tabular}

\section{*Excluding hayfever.}

†Prebronchodilator values with childhood asthmatics reclassified (see the Methods section).

$\ddagger$ Respiratory symptoms and airflow obstruction.

$\mathrm{GOLD}=\mathrm{FEV}_{1} / \mathrm{FVC}<0.7 ; \mathrm{NICE}=\mathrm{FEV}_{1} / \mathrm{FVC}<0.7$ and $\mathrm{FEV}_{1}<80 \%$ predicted; single

$\mathrm{LLN}=\mathrm{FEV}{ }_{1} / \mathrm{FVC}<5$ th percentile of healthy never-smoking population; double $\mathrm{LLN}=\mathrm{FEV}_{1} /$

$\mathrm{FVC}<5$ th percentile and $\mathrm{FEV}_{1}<5$ th percentile.

$\mathrm{COPD}$, chronic obstructive pulmonary disease; $\mathrm{FEV}_{1}$, forced expiratory volume in $1 \mathrm{~s}$; FVC, forced vital capacity; GOLD, Global Initiative for Chronic Obstructive Lung Disease; LLN, lower limit of normal; MRC, Medical Research Council; NICE, National Institute for Health and Clinical Excellence.

while for never smokers rates did not rise above $1 \%$ until age 60 years.

\section{Comparing a model of an active approach against an opportunistic-only approach to case finding}

Analysis of the HSE showed that $48 \%$ of the target group (ever smokers aged 40-79 years) reported relevant respiratory symptoms. Of these, $16 \%$ demonstrated airways obstruction, and therefore, for every 10000 ever-smoking patients in this age group we would expect 768 undiagnosed cases (or 7.7 per 100).

Figure 1 details the flow of patients through both arms of the case-finding model taking into account other parameters such as response rates. The active approach to case finding would yield $70 \%$ more new cases than the opportunistic approach (3.8 vs 2.2 new cases per 100 ever smokers targeted), giving a rate difference of 1.6 per 100 targeted and identifying $49 \%$ of the expected cases. Sixty-three ever smokers would need to be actively targeted to identify one extra case of COPD, over and above the opportunistic approach. Of these new cases, 39.2\% would have at least MRC grade 3 dyspnoea, and $26.8 \%$ stage III/IV disease (50.9\% with either) and could benefit immediately from effective disease-modifying treatments.

\section{Sensitivity analyses}

Table 4 and figure 3 illustrate the effect of varying key parameters on the relative benefit of the systematic approach, and highlight the plausible ranges. The model is sensitive to changes in the proportion of the target group with respiratory symptoms (a range of $30-70 \%$ alters the rate difference from 1.0 to 2.3 per 100) and to the proportion of those with respiratory symptoms having COPD on spirometry (a range of $10-30 \%$ alters the rate difference from 1.0 to 3.0 per 100 targeted). The key modifiable parameters are the response rate to postal questionnaires, the probability the respiratory questionnaire is administered opportunistically and, to some extent, the spirometry uptake rates. A variation in postal response of $30-70 \%$ would result in a rate difference of 1.0-2.2 per 100 targeted. In contrast, as practices administer more questionnaires, the advantage of the active approach is attenuated.

\section{Modelling alternative targeting strategies}

Targeting those aged over 50 increases the efficiency of an active approach compared with an opportunistic-only approach (NNT 47 vs 65 ) although marginally less sensitive than targeting the full $40-79$ year age range (44\% vs $49 \%$ expected) (see online table).

Targeting current smokers aged $\geq 45$ years and ex-smokers aged $\geq 55$ years would improve the efficiency of the active approach without losing many cases (NNT $=45 ; 47 \%$ total identified).

An active strategy without concurrent opportunistic case finding (ie, postal questionnaire only) would result in a difference of only 0.5 per 100 targeted over the base case, and identify one-third fewer cases than with the combined approach.

Although restricting the target group to those with dyspnoea only would identify patients with more severe disease $(50.4 \%$ with MRC grade 3 dyspnoea vs $39.2 \%$ in the base case), the active approach would then have a relatively smaller benefit and pick up fewer undiagnosed cases than the base case.

Use of the single LLN criteria to define cases had little overall effect, although cases were generally milder. While double LLN decreased the yield in both arms, and reduced the advantage of the active approach, a higher proportion of more severe cases would be identified (59.0\% eligible for disease-modifying treatment).

\section{DISCUSSION}

In this analysis of nationally representative data of $>20000$ adults aged $\geq 30$ years, we identified a substantial amount of undiagnosed clinically significant COPD (patients with both respiratory symptoms and airflow obstruction). Overall prevalence in this age group was $4.7 \%$, consistent with internationally available data, ${ }^{1}$ but lower than many recent studies reporting spirometrically defined COPD only. ${ }^{4} 629$

A total of $86.5 \%$ of those with clinically significant COPD did not report previously diagnosed chronic bronchitis/emphysema. 
Table 3 Comparison of the characteristics of diagnosed and undiagnosed clinically significant COPD in England

\begin{tabular}{lll}
\hline & Undiagnosed & Diagnosed \\
\hline $\begin{array}{l}\text { Number of participants } \\
\text { Age (years) }\end{array}$ & 840 & 131 \\
$30-39$ & $13(1.6 \%)$ & 0 \\
$40-49$ & $70(8.3 \%)$ & $8(6.1 \%)$ \\
$50-59$ & $137(16.3 \%)$ & $19(14.5 \%)$ \\
$60-69$ & $257(30.6 \%)$ & $41(31.3 \%)$ \\
$70-79$ & $266(31.7 \%)$ & $53(40.5 \%)$ \\
$\geq 80$ & $97(11.6 \%)$ & $10(7.6 \%)$ \\
& & $(p=0.2)$
\end{tabular}

Sex

Male

Female

Smoking status

Current

Ex-regular

Never regular

Reported respiratory symptoms

Dyspnoea

MRC grade 3 or worse

Wheeze

Chronic cough

Chronic phlegm

Frequent winter bronchitis

Any of the above respiratory symptoms

Severity of airflow obstruction*

Stage $\left(\mathrm{FEV}_{1} \%\right.$ predicted)

$\begin{array}{lll}\text { II }(50-80 \%) & 628(74.8 \%) & 55(42.0 \%) \\ \text { III }(30-49 \%) & 181(21.6 \%) & 52(39.7 \%) \\ \text { IV }(<30 \%) & 31(3.7 \%) & 24(18.3 \%)(p<0.001) \\ \text { ikely to benefit most from disease- } & 417(49.6 \%) & 104(79.4 \%)(p<0.001)\end{array}$

Likely to benefit most from disease-

modifying treatment $\left(\mathrm{FEV}_{1}<50 \%\right.$

predicted or MRC grade 3 dyspnoea)

${ }^{*}$ Stage according to GOLD (Global Initiative for Chronic Obstructive Lung Disease) guidelines.

COPD, chronic obstructive pulmonary disease; $\mathrm{FEV}_{1}$, forced expiratory volume in $1 \mathrm{~s}$; MRC, Medical Research Council.

This is comparable with other studies, despite their broader diagnostic criteria. ${ }^{4-6}$ A substantial burden of undiagnosed disease is not confined to milder cases; over half would be eligible for combination or anticholinergic inhaler treattment to reduce hospitalisation and mortality or pulmonary rehabilitation, which is effective in improving quality of life. Milder cases would be eligible for symptomatic relief, smoking cessation, and influenza and pneumococcal vaccinations under current guidance, ${ }^{9}$ and reports of subgroup analyses also indicate that inhalers may reduce hospitalisation and mortality in these patients too. ${ }^{30} 31$ This clearly demonstrates the need for case finding.

Our analyses of the HSE suggest that case finding among responding ever smokers aged 40-79 years would result in a yield of $7.7 \%$; this is somewhat lower than most previous reports ${ }^{11} 1327$ but partly reflects the tighter requirement in our COPD case criteria for the concurrent presence of both symptoms and airflow obstruction. The yield would be further reduced if more stringent spirometric criteria, such as double LLN, were used. We have also demonstrated that the addition of active to opportunistic case finding could potentially identify $70 \%$ more cases. This result is unaltered by varying the definition of COPD. Direct mailing alone to eligible patients (without the back-up of opportunistic discovery for non-respondents) would only have small benefits over a reasonably well-implemented opportunistic approach.
Prevalence of undiagnosed COPD

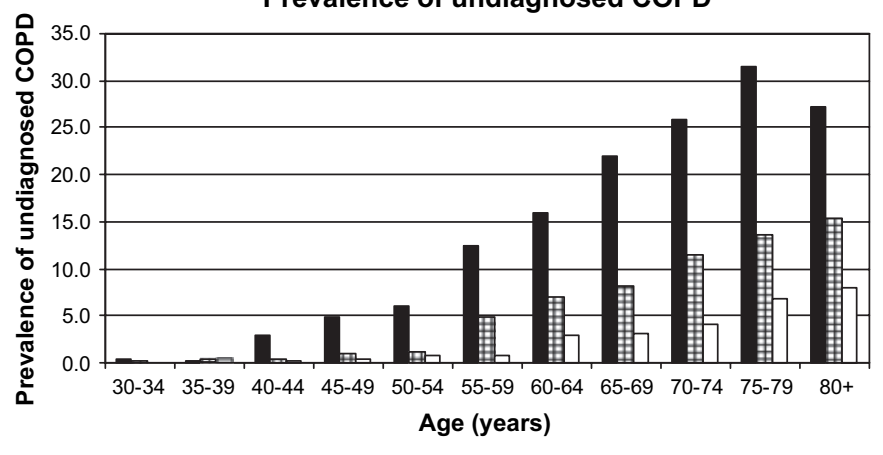

- Current smokers 由 Ex-smokers $\square$ Never smokers

Figure 2 Prevalence of undiagnosed clinically significant chronic obstructive pulmonary disease (COPD) by age and smoking history in participants of the 1995-1996 Health Survey for England aged $\geq 30$ years. (Clinically significant indicates respiratory symptoms and airways obstruction according to National Institute for Health and Clinical Excellence criteria.)

In England, there are an estimated 10.9 million ever smokers aged 40-79 years without a diagnosis of COPD. ${ }^{32}{ }^{33}$ Implementation of such an active case-finding approach could identify 403073 new cases. Of these, 108024 (26.8\%) may be eligible for combination inhalers under current guidance. Assuming that patients with more severe undiagnosed COPD are hospitalised at a similar rate to those who are diagnosed, treatment with combination inhalers could reduce the number of annual hospitalisations by at least 3328 (combination treatment reduces on average 0.03 COPD-related hospitalisations per person $^{30}$ ), 1401 more than with an opportunistic-only approach, and could also prevent 2885 deaths over 3 years. ${ }^{30}$ This is a conservative estimate, as patients could also benefit from pulmonary rehabilitation, smoking cessation and single inhalers, all with health benefits. Furthermore, even those with less severe disease ( $\mathrm{FEV}_{1}>50 \%$ predicted) may benefit from combination inhalers or anticholinergic inhalers.

Our models show that modifying the target population for case finding (eg, smokers aged $>45$ and ex-smokers aged $>55$ ) could increase yield and improve the efficiency while detecting a similar proportion of all undiagnosed COPD.

\section{Limitations}

The estimates for most analyses were taken from the HSE 1995-1996. These data have the advantage of being representative of the English population and were obtained using standardised methodology, but the HSE was not designed for this purpose and therefore suffers from some limitations. The spirometry standards may not be as rigorous as those now recommended by the American Thoracic Society (ATS). Postbronchodilator spirometry was not available, and assumptions made to help separate patients with COPD from those with asthma may have misclassified COPD in either direction. Participants were not explicitly questioned about whether they had ever been diagnosed with COPD; they were asked to report any longstanding illness which was coded as chronic bronchitis/ emphysema or 'other respiratory conditions'. The latter included 'bad chest' or 'chesty cough', which may signify a diagnosis of COPD. The reported diagnosis of COPD was likely to be underestimated; indeed the diagnosed prevalence of COPD in 1997 was $1.5 \%{ }^{34}$ compared with the $1.0 \%$ reported in the 1995-1996 HSE population. However, even if the number of 
Table 4 Sensitivity analysis

\begin{tabular}{|c|c|c|c|c|c|c|}
\hline \multirow[t]{2}{*}{ Parameter } & \multicolumn{2}{|c|}{$\begin{array}{l}\text { New cases } \\
\text { (per } 100 \text { targeted) }\end{array}$} & \multirow[t]{2}{*}{$\begin{array}{l}\text { Rate difference } \\
\text { (per } 100 \text { targeted) }\end{array}$} & \multirow[t]{2}{*}{$\begin{array}{l}\% \text { additional cases } \\
\text { detected with active } \\
\text { approach }\end{array}$} & \multirow[t]{2}{*}{ NNT } & \multirow[t]{2}{*}{$\begin{array}{l}\text { Proportion of expected } \\
\text { cases in the community } \\
\text { detected with active approach }\end{array}$} \\
\hline & Active & Opportunistic only & & & & \\
\hline \multicolumn{7}{|c|}{ Model assumptions } \\
\hline \multicolumn{7}{|c|}{ Proportion with any respiratory symptom } \\
\hline 0.3 & 2.4 & 1.4 & 1.0 & $70 \%$ & 101 & 0.49 \\
\hline 0.1 & 2.4 & 1.4 & 1.0 & $70 \%$ & 101 & 0.49 \\
\hline 0.2 & 4.7 & 2.8 & 2.0 & $70 \%$ & 50 & 0.49 \\
\hline 0.3 & 7.1 & 4.1 & 3.0 & $70 \%$ & 34 & 0.49 \\
\hline \multicolumn{7}{|c|}{ Process assumptions } \\
\hline \multicolumn{7}{|c|}{ Questionnaire response rate (postal) } \\
\hline 0.3 & 3.2 & 2.2 & 1.0 & $43 \%$ & 105 & 0.41 \\
\hline \multicolumn{7}{|c|}{ GP asks questionnaire in surgery } \\
\hline 0.3 & 3.3 & 1.3 & 2.0 & $154 \%$ & 49 & 0.41 \\
\hline 0.7 & 4.2 & 3.1 & 1.2 & $37 \%$ & 87 & 0.55 \\
\hline \multicolumn{7}{|c|}{ Spirometry uptake rate } \\
\hline 0.5 & 2.7 & 1.6 & 1.1 & $70 \%$ & 88 & 0.35 \\
\hline 0.9 & 4.9 & 2.8 & 2.0 & $70 \%$ & 49 & 0.63 \\
\hline \multicolumn{7}{|c|}{ Spirometry accuracy } \\
\hline 0.9 sensitivity & 3.4 & 2.0 & 1.4 & $70 \%$ & 70 & 0.44 \\
\hline 0.8 sensitivity & 3.0 & 1.8 & 1.3 & $70 \%$ & 79 & 0.39 \\
\hline
\end{tabular}

Numbers in bold are referred to in the text.

* Clinically significant COPD defined as respiratory symptoms and airways obstruction (National Institute for Health and Clinical Excellence criteria).

COPD, chronic obstructive pulmonary disease; GP, general practitioner; NNT, number needed to target with the active approach to identify one additional new case over opportunistic only

diagnosed cases of COPD were double, there would still have been $>70 \%$ undiagnosed. This misclassification should not affect the case-finding model which focuses purely on those who had no previous diagnosis.
Smoking habits and the definitions of COPD may have changed since data collection 12 years ago, and the diagnosis of COPD in the UK may have improved with the advent of the Quality Outcomes Framework. However, in 1997, the diagnosed
Figure 3 Effect of varying key parameters on rate difference of active versus opportunistic case finding for chronic obstructive pulmonary disease (COPD). For each of the following eight parameters, the graphs indicate how changes in the estimates of the parameter (proportions from 0 to 1 ) affect the estimates of relative effectiveness of the active approach. Bold portions of the line indicate the most plausible range of interest. (a) Proportion of target population with specified respiratory symptoms. (b) Proportion of those with respiratory symptoms having clinically significant COPD. (c) Probability that patients with COPD visit their GP (general practitioner) at least once per year. (d) Probability that patients without COPD visit their GP at least once per year. (e) Uptake in response to postal questionnaire. (f) Probability GP/nurse will ask respiratory questions opportunistically. (g) Proportion of patients responding to questions administered at the surgery. (h) Uptake of spirometry.
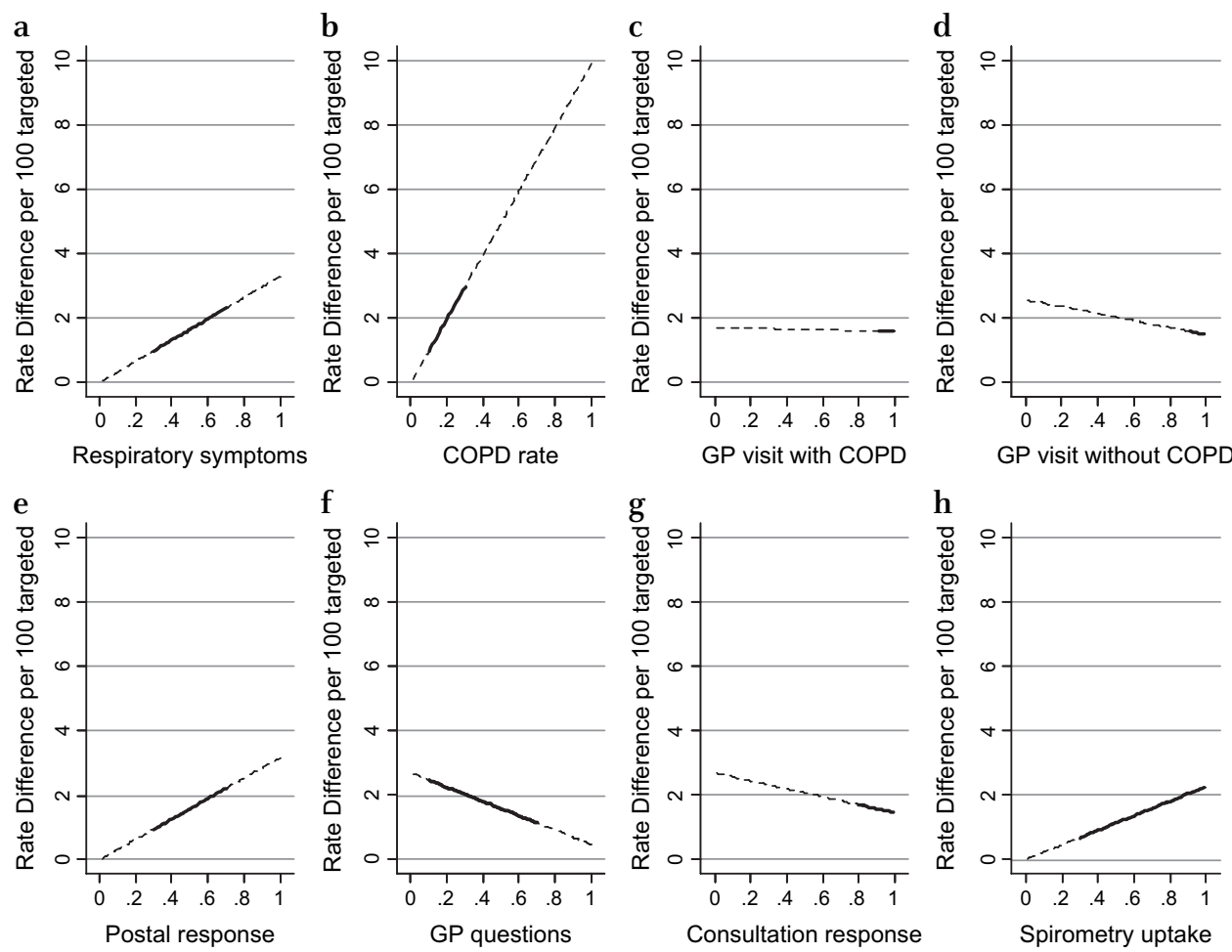

h

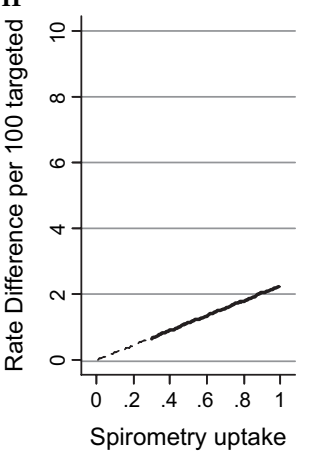


prevalence of COPD was $\sim 1.5 \%{ }^{34}$ and in $20061.4 \%{ }^{35}$ Even if the proportion of undiagnosed COPD varied, the case-finding model will remain valid.

\section{Implications}

We have demonstrated substantial undiagnosed COPD in the community of $\sim 4 \%$ among adults $\geq 30$ years in England. Identifying these cases would potentially have huge resource implications but could prevent a significant number of annual hospitalisations. The model is based on a simple spreadsheet and could be adapted to different settings and countries where rates of smoking, prevalence of respiratory symptoms and prevalence of airways obstruction might vary.

The model relies on estimates from the literature, though some of the process inputs could vary greatly. In order for the cost-effectiveness of both approaches to be fully evaluated, wellconstructed primary studies are needed with examination of different scenarios. For example, the case for applying financial incentives to GPs to ask respiratory questions versus prioritising resources for ensuring optimal questionnaire response rate could be evaluated, as could the potential for more sensitive algorithms to identify patients at risk, and different methods of delivering spirometry.

In summary, our study adds to the evidence around case finding for COPD by confirming and quantifying the extent of undiagnosed clinically significant COPD and providing a simple model of two alternative case-finding approaches. This can feed into the development of case-finding strategies likely to be needed in the new National Clinical Strategy in England and also provides a flexible model which can be applied to other healthcare settings.

Acknowledgements We are grateful to the UK Data Archive, University of Essex, and the Health Survey for England 1995, 1996, 2001 and 2007 for providing access to their data.

\section{Competing interests None.}

Contributors RJ, KL, PA, KKC and MM contributed and developed the initial idea, and $\mathrm{JA}, \mathrm{DF}$ and JM additionally contributed to the case-finding component and model. RJ and KL undertook analyses of the HSE, RJ created the initial model and JM advised on and undertook statistical testing and sensitivity analyses of the model. RJ wrote the paper with input and advice from all authors. KKC is the guarantor for the paper. All authors take responsibility for the integrity of the data and accuracy of the data analysis.

Provenance and peer review Not commissioned; externally peer reviewed.

\section{REFERENCES}

1. Halbert RJ, Natoli JL, Gano A, et al. Global burden of COPD: systematic review and meta-analysis. Eur Respir J 2006;28:523-32

2. On the state of the Public Health. Annual report of the chief medical officer http://www.dh.gov.uk/prod_consum_dh/groups/dh_digitalassets/@dh/@en/ documents/digitalasset/dh $\overline{4} 115781$. pdf (accessed 5 May 2010).

3. Gruffydd-Jones K. A national strategy for the management of chronic obstructive pulmonary disease (COPD) in England: aiming to improve the quality of care for patients. Prim Care Resp J 2008;17(Suppl 1):S1-8.

4. Mannino DM, Gagnon RC, Petty TL, et al. Obstructive lung disease and low lung function in adults in the United States: data From the National Health and Nutrition Examination Survey, 1988-1994. Arch Intern Med 2000:160:1683-9.

5. Bednarek M, Maciejewski J, Wozniak M, et al. Prevalence, severity and underdiagnosis of COPD in the primary care setting. Thorax 2008;63:402-7.

6. Shahab L, Jarvis MJ, Britton J, et al. Prevalence, diagnosis and relation to tobacco dependence of chronic obstructive pulmonary disease in a nationally representative population sample. Thorax 2006;61:1043-7.

7. US Preventive Services Task Force. Screening for chronic obstructive pulmonary disease using spirometry: US Preventive Services Task Force Recommendation Statement. Ann Intern Med 2008;148:529-34.
8. Wilt TJ, Niewoehner D, MacDonald R, et al. Management of stable chronic obstructive pulmonary disease: a systematic review for a clinical practice guideline. Ann Intern Med 2007;147:639-53.

9. The National Collaborating Centre for Chronic Conditions. Chronic obstructive pulmonary disease. National clinical guideline on management of chronic obstructive pulmonary disease in adults in primary and secondary care. Thorax 2004:59 (Suppl 1):1-232

10. Wilt T, Kim C-B, Kane R, et al. Use of spirometry for case finding, diagnosis and management of chronic obstructive pulmonary disease (COPD). Evidence Reportl Technology assessment No 121 (prepared by the Minnesota Evidence-based practice Center under Contract No 290-02-0009) 2005;AHRO Publication No. 05-E017-2. Rockville, MD: Agency for Healthcare Research and Quality, 2005.

11. van Schayck CP, Loozen JMC, Wagena E, et al. Detecting patients at a high risk of developing chronic obstructive pulmonary disease in general practice: cross sectional case finding study. BMJ 2002;324:1370.

12. Buffels J, Degryse J, Heyrman J, et al. Office spirometry significantly improves early detection of COPD in general practice: the DIDASCO study. Chest 2004;125:1394-9.

13. Tinkelman D, Price D, Nordyke R, et al. COPD screening efforts in primary care: what is the yield? Prim Care Resp J 2007;16:41-8.

14. Joint Health Surveys Unit of Social and Community Planning Research and University College London. Health survey for England, 1995 [computer file]. 3rd edn. Colchester, Essex: UK Data Archive [distributor], 26 March 2001 SN: 3796, 2001.

15. Joint Health Surveys Unit of Social and Community Planning Research and University College London. Health survey for England, 1996 [computer file]. 3rd edn. Colchester, Essex: UK Data Archive [distributor], March 2001 SN: 3886, 2001.

16. Global Initiative for Chronic Lung Disease. Global strategy for the diagnosis, management and prevention of chronic obstructive pulmonary disease. http://www. goldcopd.org/Guidelineitem.asp? $|1=2 \xi| 2=1$ \&intld $=2003$. February 2009 laccessed 5 May 2010)

17. Quanjer P, Tammeling G, Cotes J, et al. Report working party Standardisation of lung function tests, European Community for Steel and Coal. Official Statement of the European Respiratory Society. Eur Respir J 1993;6(Suppl 16):5-40.

18. Culver B. Interpretation of spirometry: we can do better than the GOLD standard Respir Care 2006:51:719-20.

19. Martinez F, Raczek A, Seifer F, et al. Development and initial validation of a selfscored COPD Population Screener Questionnaire (COPD-PS). COPD 2008;5:85-95

20. Price D, Tinkelman D, Halbert RJ, et al. Symptom-based questionnaire for identifying COPD in smokers. Respiration 2006;73:285-95.

21. Calverley PMA, Nordyke R, Halbert RJ, et al. Development of a population-based screening questionnaire for COPD. COPD 2005;2:225-32.

22. Jordan RE, Hawker JI, Ayres JG, et al. Effect of social factors on winter hospital admission for respiratory disease: a case control study of older people in the UK. Br J Gen Pract 2008; 58:e1-9.

23. Fitzmaurice DA, Hobbs FDR, Jowett $S$, et al. Screening versus routine practice in detection of atrial fibrillation in patients aged 65 or over: cluster randomised controlled trial. BMJ 2007;335:383

24. ORESEARCH and The Information Centre for health and social care. Trends in consultation rates in general practice 1995 to 2006: Analysis of the QRESEARCH database. http://www.ic.nhs.uk/statistics-and-data-collections/primary-care/generalpractice/trends-in-consultation-rates-in-general-practice-1995-2006 laccessed 5 May 2010)

25. Britton M. The burden of COPD in the UK: results from the confronting COPD survey Respir Med 2003;97(Suppl 3):S71-9.

26. Morgan S, Mant D. Randomised trial of two approaches to screening for atrial fibrillation in UK general practice. Br J Gen Pract 2002:52:373-80.

27. Vandevoorde J, Verbanck S, Gijssels L, et al. Early detection of COPD: a case finding study in general practice. Respir Med 2007;101:525-30.

28. Yawn BP, Enright PL, Lemanske RF, et al. Spirometry can be done in family physicians offices and alters clinical decisions in management of asthma and COPD. Chest 2007;132:1162-8.

29. Buist AS, McBurnie M, Vollmer WM, et al. International variation in the prevalence of COPD (The BOLD Study): a population-based prevalence study. Lancet 2007;370:741-50.

30. Calverley PMA, Anderson JA, Celli B, et al. Salmeterol and fluticasone propionate and survival in chronic obstructive pulmonary disease. N Engl J Med 2007;356:775-89.

31. Decramer $\mathbf{M}$, Celli B, Kesten $\mathrm{S}$, et al. Effect of tiotropium on outcomes in patients with moderate chronic obstructive pulmonary disease (UPLIFT): a prespecified subgroup analysis of a randomised controlled trial. Lancet 2009;374:1171-8.

32. National Centre for Social Research and University College London. Department of Epidemiology and Public Health. Health Survey for England, 2007 [computer file]. Colchester, Essex: UK Data Archive [distributor], February 2009 SN: 6112, 2009.

33. Office for National Statistics. Mid-2007 UK, England and Wales, Scotland and Northern Ireland population estimates. http://www.statistics.gov.uk/statbase/ Product.asp?vlnk=15106 (accessed 5 May 2010)

34. Soriano JB, Maier WC, Egger $\mathrm{P}$, et al. Recent trends in physician diagnosed COPD in women and men in the UK. Thorax 2000;55:789-94.

35. Department of Health (England). Quality and outcomes framework. http://www dh.gov.uk/en/Healthcare/Primarycare/Primarycarecontracting/QOF/index.htm (accessed 5 May 2010) 